\title{
Stuck on repeat: Why do we continue to ruminate?
}

\author{
Jodie Louise Russell ${ }^{1}$ id
}

Received: 31 December 2020 / Accepted: 17 August 2021 / Published online: 6 September 2021

(c) The Author(s) 2021

\begin{abstract}
An oft misattributed piece of folk-wisdom goes: "Insanity is doing the same thing, over and over again, but expecting different results." In many cases, we don't just do things repeatedly but think over the same topics repeatedly. People who ruminate are not often diagnosed as insane-most of us ruminate at some point in our livesbut it is a common behaviour underlying both depression and anxiety (Nolen-Hoeksema in J Abnorm Psychol 109(3):504, 2000). If rumination is something we all do at some time, what is it about ruminative thought that makes it 'sticky' and difficult to stop for the worst sufferers? In order to answer this question, I will present a plausible account of how ruminative behaviour becomes entrenched to the point where sufferers of anxiety and depression simply cannot make meaning from the world except in terms of the kinds of behaviours, actions and thoughts they have become reliant on. I develop my account from Barrett's theory of constructed emotion (2006, 2011, 2014) using the work of Merleau-Ponty (Phenomenology of perception, Taylor and Francis Group. (Online), ProQuest Ebook Central, 2012. https://ebookcentr al.proquest.com/lib/ed/detail.action?docID=1433878. Accessed 29 Dec 2020) in order to bridge the gap between the explicit thought we experience-an important part of the lived experience of rumination. To conclude, I will apply my account to Wu and Dunning's (Rev General Psychol 22(1):25-35, 2018; Hypocognitive mind: How lack of conceptual knowledge confines what people see and remember, 2019. https://doi.org/10.31234/osf.io/29ryz) theory of hypocognition to further illuminate the particular cognitive qualities that can be experienced by ruminators, i.e. a prohibited access to particular emotion concepts.
\end{abstract}

Keywords Rumination $\cdot$ Anxiety $\cdot$ Depression $\cdot$ Emotions $\cdot$ Concepts

\footnotetext{
This article belongs to the topical collection "Worry and Wellbeing: Understanding the Nature, Value, and Challenges of Anxiety", edited by Charlie Kurth and Juliette Vazard.

Jodie Louise Russell

s1402420@ed.ac.uk

1 Department of Philosophy, School of Philosophy, Psychology and Language Science, University of Edinburgh, Edinburgh, Scotland
} 


\section{Introduction: the problem with rumination}

An oft misattributed piece of folk-wisdom goes: "Insanity is doing the same thing, over and over again, but expecting different results." In many cases, we don't just do things repeatedly but think over the same topics repeatedly. People who ruminate are not often diagnosed as insane-most of us ruminate at some point in our livesbut it is a common behaviour underlying both depression and anxiety (Nolen-Hoeksema, 2000). If rumination is something we all do at some time, what is it about ruminative thought that makes it 'sticky' and difficult to stop for the worst sufferers?

The greatest proportion of the literature on rumination by Nolen-Hoeksema and colleagues (Aldao \& Nolen-Hoeksema, 2012; McLaughlin \& Nolen-Hoeksema, 2011; Nolen-Hoeksema, 1991, 2000) has focused exclusively on dysphoric rumination-repetitive negative thoughts - and its link to depression and anxiety. They define rumination as:

behaviors and thoughts that focus one's attention on one's depressive symptoms and on the implications of these symptoms [...] individuals simply think about or talk about how unmotivated, sad, and lethargic they feel without doing anything to relieve their symptoms, or they worry about the meanings of the symptoms without making plans to change their situation. (Nolen-Hoeksema, 1991 p. 569)

However, repetitive thought (RT) need not always be negative or, indeed, pathological. In a wider examination of the literature, Watkins (2008) has found evidence that positively valenced RT can be both helpful and harmful for one's mental health, and there are even cases where negatively valenced RT can be helpful. Moreover, Antrobus and Bortolotti (2016) argue that there may be epistemic benefit in the kinds of beliefs dysphoric ruminators hold, and these beliefs may play an important role in one's sense of identity. ${ }^{1}$ We might infer from this that there is nothing inherently pathological about repetitively thinking about upsetting things but this raises the question as to why RT seems to be a significant factor in enhancing or prolonging depressive symptoms (as in Nolen-Hoeksema, 1991). RT might have this effect, it could be argued, because RT takes place in a background of other conditions directing the individual's cognition, such as the valence or mood the person is already in, the effect of the immediate environment (Watkins, 2008), and even the individual's beliefs about how helpful RT is for solving problems (Watkins \& Baracaia, 2001). These background conditions may help us distinguish when RT is going to help or hinder us (Watkins, 2008) but this is not a sufficient explanation of why certain negative thoughts become repetitive or even compulsive (see Watkins \& Baracaia, 2001), especially in the pathological case. People who ruminate may do so while observing that there are both benefits and drawbacks to the problem-solving strategy (Watkins \& Baracaia, 2001) although some evidence suggests that rumination

\footnotetext{
1 Similarly, research by Vazard (2019) suggests there is some epistemic value to anxious doubting, when it is adaptive to do so, and Kurth (2018) argues that anxiety can be both instrumentally and intrinsically valuable under some conditions.
} 
doesn't actually help to solve problems (Lyubomirsky \& Nolen-Hoeksema, 1995). While this correlative (or even causal) connection is made, there is still a gap in the literature for an account of why ruminating feels the way that it does as wells as its particular mechanics. As an essential part of the experience of ruminating, people feel compelled to ruminate, feel trapped in the cycle of thought, and rumination (even more importantly for Nolen-Hoeksema and colleagues) makes them feel depressed or anxious. I therefore intend to provide a plausible account of how rumination develops in near clinical experiences of depression and anxiety in such a way that would account for the phenomenal qualities of RT.

Much philosophical work has already been done to describe the phenomenological structure of psychopathology (see Colombetti, 2013, for an overview). Individuals with depression and anxiety are often characterised as being 'disturbed' (e.g., from an existential state: Jelscha, 2018), 'alienated' (from one's agency: Slaby et al., 2013), experiencing an 'estrangement' (from interpersonal experience: Ratcliffe, 2018) a 'disruption' (in future-directed affective intentionality: Maiese, 2020) or their illness is a result of a break-down of some process (see Fuchs 2001 and 2009 in Colombetti, 2013). However, little work has been done to describe in detail the specific symptoms, such as rumination, that underly multiple mental disorders which are common to the mentally ill and mentally well alike. Furthermore, current accounts of depression and anxiety don't elucidate how one becomes 'disturbed' or 'alienated' in the first place. My concern is that by construing mood disorders as broadly as they do in the phenomenology of psychopathology and 4E literature, we cannot explain how finer grained symptoms like rumination arise in comorbid disorders or between clinical and non-clinical populations. By focussing on symptoms like rumination, we could shine a light on 'big-picture' problems in the Philosophy of Psychiatry, like how people become mentally ill in the first place. By examining how rumination develops from non-clinical to clinical population we might understand better how a patient becomes alienated from these sense-making actions that the philosophical literature highlights as key to mental wellbeing. My account below closely aligns with the $4 \mathrm{E}$ paradigm insofar as my account paints a picture of the mechanisms of RT not limited to simply activity in the brain but distributed through the body and I argue that action in the world is also a contributor to RT. I hope, however, to provide a more grounded account, for enactivists, to explain how dysphoric rumination occurs in cases of mental disorder.

While I cannot claim to provide the 'definitive' account of RT, an integrated model of rumination that touches on underlying bodily processes as well as the lived experience of the ruminator is yet to be proposed. My intention, therefore, is to present a plausible account of how ruminative behaviour becomes entrenched to the point where sufferers of anxiety and depression simply cannot make meaning from the world except in terms of the kinds of behaviours, actions and thoughts they have become reliant on. In doing so, I hope to lay the groundwork for fruitful investigation into this particular cognitive behaviour as well as depression and anxiety more widely. I hope also to provide an account with continuity; I will suggest how dysphoric rumination in near clinical cases of depression and anxiety are a development of the kinds of thinking and sense-making in non-clinical cases. I ground my account in terms of the sense-making activity of emotion categorisation, as developed from 
Barrett's theory of constructed emotion (2006, 2011, 2014). Barrett's account seeks to explain the phenomenal qualities of emotions based on underlying processes and mechanisms that generate affect, instantiated in the body and action in the world. These underly our individual sense-making capabilities whether we have a mental disorder or not. However, I will find her theory lacking in two aspects: she provides too stringent a mapping of sub-personal emotional processes, stored concepts and the words we have access to on the personal level, and her theory alone cannot be stretched to explain ruminative behaviour in clinical cases. Her account may also overly make use of the term 'representation', which would be inconsistent with the enactive approach I wish to make. Therefore, I will take forward a particular interpretation of her work (argued below) as well as highlight the unique contribution she makes that I wish to draw upon.

In response to these challenges, I include the work of Merleau-Ponty (2012) in order to bridge the gap between the propositional thoughts we experience during RT and the underlying affective processes which give these thoughts the negative emotional 'tinge' experienced by dysphoric ruminators. In so doing, I move away from Barrett's unnecessarily strict requirement that we must have a word for an emotion to experience it. To further adapt Barrett's theory to account for the experienced of dysphoric rumination, I derive that emotion concepts interact and form associative links. Lastly, I will apply my account to Wu and Dunning's $(2018,2019)$ theory of hypocognition to further illuminate the particular cognitive qualities that can be experienced by ruminators, i.e. a prohibited access to particular emotion concepts. I will argue that the application of some concepts prevent the application of others and, as a consequence, reappraisal becomes a near impossible task, thus dysphoria (the application of negatively valenced emotion concepts within depression and anxiety) perpetuates. Barrett's theory can thus be used to make sense of the hypocognitive qualities of dysphoric rumination which lead to what Teasdale $(1983,1988)$ describes as a 'vicious cycle'.

\section{Barrett and emotion concepts}

Barrett's highly influential theory of constructed emotion was originally formulated to solve the paradox of squaring people's individuated experiences of emotion with the fact that science is yet to find underlying fingerprints for these distinct emotions (Barrett, 2006). I don't wish to delve into the issue of emotions as natural kinds but Barrett's model also tries to integrate affect into cognition and perception (see Barrett, 2017), which makes it an appropriate model to apply to rumination as it also integrates emotional experience with behaviour, perception and action. As NolenHoeksema describes above, rumination involves all of these factors. I think this model can elucidate on some of the features of RT, e.g. its feeling of compulsiveness, as well as help us understand the repetitive negative affect underlying experiences of depression and anxiety. Firstly, however, we must accept the assumption that the processes of emotional categorization are involved in RT. This assumption is justified on the basis that RT is valenced along a positive and negative scale (see Watkins, 2008) and, since RT comes with this emotional phenomenology, it would 
appear to be enmeshed in the system which produces emotional experience. I suggest that by looking at how emotional experience is generated we can make inferences as to how the very same mechanisms for emotional experience can produce the experiences of those who get stuck ruminating dysphorically. What I plan to take from Barrett, here, is a temporal account of how experiences in RT are consistently negative over time before drawing on Merleau-Ponty (2012) to understand how particular propositional thoughts get enmeshed in this emotional system.

\subsection{Barrett's account of emotional experience}

Barrett understands emotion not to be mechanical reactions to external stimuli (Barrett, 2006) but as mental events or constructions of interacting psychological and biological systems (Barrett, 2011). To elaborate, there are two relevant basic processes going on in the background of affective experience: our simple bodily processes that feed interceptive information to our perceptual system and our conceptual knowledge or, more simply, what we "know" about emotions, including particular words and phrases (Barrett, 2011). These systems interact in order to combine sensory stimulus from the environment with the interoceptive stimulus from our body so we can navigate the world (Barrett, 2011). Core affect provides the generally polarizing experience of pleasant/unpleasant that underlies emotional experiences; it is a neurophysiological state which acts like a barometer (Barrett, 2011) to assess your relative position to the world (Russell, 2003) in order to calculate, for Barrett (in Barrett, 2017; Barrett et al., 2016), the costs of certain courses of action on bodily resources for the purposes of achieving 'allostasis', or the physiological equilibrium for the organism. Core affect provokes and guides meaning making behaviour in order to reach this allostatic balance, which involves looking for causes of affective change (Russell, 2003). We can percieve changes of core affect on the conscious level, and when a change occurs an object is attributed as the cause which makes the organism attend to and interact with the object in certain ways, giving the object an 'affective quality' (i.e. makes the bear frightening, the partner loving, the doughnut delicious) (Russell, 2003). By attributing a cause we can meaningfully and reliably navigate our environment; if a party clown gives me the chills- thus having potentially disastrous consequences for allostasis-I will make sure to avoid that clown. Further to this, according to Russell (2003), core affect draws people's attention to things in the environment that produce similar affective experiences. In order to find out the cause of unpleasant experiences, organisms seek out events that produce similar experiences to ascertain a common cause, so I might not just avoid that particular clown but all future clowns or anything else that gives me the same 'creeped out' feeling. The processes of comparing similarities across emotional events is the act of categorization (Barrett, 2006; Russell, 2003).

When core affect is categorized, i.e. when the similarities of present bodily and environmental changes are compared to similar past instances, which are grouped and stored in the brain (known as a concept) (Barrett, 2006), we have an emotional experience. It is important to note here that emotion concepts are the stored summaries of previous categorizations, not the words themselves which typically label 
similar experiences (like anger, happiness or sadness). However, Barrett takes words themselves to play a pivotal, top-down influence in shaping the emotional experience-a requirement for the experience of emotion I take to be too strict (see below). For the purposes of my argument, I take the term 'concept' not to mean abstract idea or mental representation (more on that below) but in Barrett's sense of stored information about past emotional events, to which current events are compared by the brain.

The act of categorizing is constantly ongoing and automatic (it is a "fundamental cognitive activity"-Barrett, 2006) and "self-perpetuating" in that the information being categorised in the present can populate the exemplars of a concept which might be brought forth in the future (Barrett 2016). In other words, in the application of the concept of 'disappointment' to my core affective state (say, of unpleasantness), and its coinciding with my dropping my ice-cream on the floor, the feeling or experience of disappointment in the moment is constructed for me. That categorization will also be stored (as multimodal summaries represented in the default mode network, see Barrett, 2017) under the concept of 'disappointment' for cases in the future where there is a similar event to me dropping my ice-cream. By categorizing as such, we make meaning from the sensory chaos going on inside and around us (Barrett 2016). The concepts act like scripts in order to help us act appropriately in broadly similar situations (Barrett, 2006). For instance, if I categorize the theft of my doughnut by a seagull as disappointing (much like dropping my ice-cream) I can understand the loss of food as analogous in both cases and the same solution to my ice-cream trouble (say, buying another one) might equally apply to the doughnut trouble. As Barrett (2006) summarises, "To categorize something is to determine what it is, why it is, and what to do with it" (p. 27).

An important consequence of Barrett's conceptual act theory is that emotions have conceptual overlap; emotions are not discrete since there is similar core affective states or external stimuli between instances of concepts. For instance, my doughnut theft might be similar to the ice-cream drop (when I was disappointed) but also that time when I was a child and my friend stole my Gameboy (when I felt angry). I could have equally been mad about the seagull stealing my doughnut. This example shows that the instances that populate the emotion concepts we apply might belong in multiple concepts and that more than one concept could be applied given a particular situation since we categorize based on similarity. This means that there will not be a single set of unique instances that make up and differentiate each emotion concept and the same emotion concept might not always apply to broadly the same situations. RT, like all of our experiences of affect, is rarely a one-dimensional emotional experience (i.e. one emotion on repeat) but a cycling of subtly different emotional experiences that form 'waves' within moods (see Fuchs, 2013). These 'similar' concepts would explain why we go through cycles of guilt, self-blame, anger, and disappointment while ruminating; these concepts bear enough resemblance (through similar core affect, for instance) to have a similar affective 'tone' but are different enough to be applicable in different situations, thus creating variety in moods. Based on this, I think there are clusters of emotion concepts, which share similar instances of categorization. It is this overlap that can become problematic and create associated emotion concepts (see Sect. 3). 
The process of categorization will also be highly context sensitive since it integrates both bodily and environmental information with stored concepts in the moment to find the right action for the present circumstances. Emotion concepts will retain some of that context sensitivity for cross-comparison at later dates, acting as a bank of learnt experience that tells what actions are appropriate in particular, but broadly similar, circumstances (Barrett et al., 2014). The important consequence here is that Barrett's model of emotion changes the nature of rumination from being simply 'in your head' repetitive thinking to an emotionally charged and actionable perception of the world. RT isn't just something one might passively do whilst staring at the wall; RT, according to Barrett's model, is a way of finding the right kinds of actions for the situations we think repetitively about. This explains why many people may ruminate despite knowing it has benefits and draw backs to solving problems (Watkins \& Baracaia, 2001); it is because by thinking through an emotionally charged situation we might find the appropriate action for the problem posed for our allostatic balance.

Despite all this useful work Barrett's theory of constructed emotion might do to elucidate on some of the phenomenology of rumination, disanalogies between Barrett's work and contemporary cognitive science in the 4E paradigm could be highlighted here. For instance, Barrett seems to make explicit representationalist claims, e.g. "All animals run an internal model of their world for the purpose of allostasis" (2017, p. 6), "[core affect] are the means by which information about the external world is translated into an internal code or representations" (2011, p. 364), and "a change in blood pressure (X1) counts as feeling offended (Y1) when category knowledge about anger is activated as a specific, embodied representation of anger (C1)" (2012, p. 420) (emphasis added). If committed to a representationalist picture of mind, her theory would be fundamentally incompatible with the enactivist arm of the $4 \mathrm{E}$ paradigm and so the work I do below to integrate an embodied conception of propositional thought will be undermined.

To circumvent this, we might permit the distinction that the brain does representational work, but it is not the case that all cognition and action is based on internal representations. This distinction is not inherently at odds with enactivism. As Boncompagni (2013) states, "[E]nactivists are not affirming that representation does not play any role. They do acknowledge the relevance of representation for certain kinds of cognition. But they deny that the paradigm of cognition should be based on representation" (p. 37). I suggest we can take forward a form of constructed emotion without a cognitivist view like thus: Barrett outlines the two basic principles of constructivism, "First, emotions are states of mind that are assembled from more basic, general causes. Second, emotions are not psychic entities, but are highly variable mental states." (Barrett, 2011, p. 362). Here, the primary understanding of emotional experience is one as a result of the organism's own dynamic activity, and is emergent from basic processes, and is thus consistent with core principles of enactivism so far (see Ward et al., 2017). However, do these emotional states of mind represent the underlying bodily processes? I suggest that while the brain may play a role in 'representing' categorizations as concepts (by storing information about the body and world for categorization), the emotional experience itself is not a representation but emergent from the sub-personal processes of categorization (which, 
for Barrett, are the processes of 'core affect', the integration of interceptive information). Representations, as stored instances of categorization, play a role in the processes of emotional experience, but we need not go as far as Barrett (2017) does in saying that organisms 'model' their environment.

The important I take from Barrett is her unique contribution to the debate that instances of emotional experiences are carried forward by us through time. The enactivists that are sympathetic to ecological psychology might agree with the allostatic focus of Barrett's organisms; they similarly argue that organisms constantly navigate the demands of the environment to remain adaptable (Di Paolo, 2005) in order to 'individuate' themselves as autonomous systems (Di Paolo \& Thompson, 2014). While Barrett (2017) describes this meaning-making as being navigated or mediated through representations, enactivists certainly don't agree that this is necessary. However, radical enactivists might struggle to account for the influence of past events on current meaning-making behaviour if they reject the notion that retrieval of information (such as that during the categorization process) involves any representational content whatsoever (see Michaelian and Sant'Anna 2019). Barrett accounts for that since emotion categorizations are stored as 'multimodal summaries' (Barrett, 2017) (which we may interpret as saying these summaries 'represent' the past information that was categorised, e.g. bodily states or environmental cues). This may seem like the organism works 'through' a representation of the body and world to act (and thus highly cognitivist) but I think Barrett would be sympathetic to the idea that the body and environment aren't just contributing factors (in a feed-forward way) to the categorization process but are also active constituents of the experience itself. Take, for instance, Barrett's (2018) flu-date case where she seems to misinterpret her symptoms of flushing due to having the flu as attraction to the person she was on a date with. At first blush, the flushing is simply 'feeding forward' information into the brain to be characterised. However, particular actions according to the categorization of 'attraction', such as flirting or hand holding, is itself a change in bodily information or environment so these changes feed back into the categorization system and thus action can shape, maintain or even change ongoing emotional experience. Therefore, action prompts categorization that prompts further action and further categorization in responsive, dynamical feed-back loops. Action will also be a way of inducing certain emotional experiences (as in the popular 'fake it until you make it' adage), such as when people act or 'pretend' to be confident to get over fears and anxieties. From this perspective, the active bodily state you are in isn't something to simply be 'captured' by the brain in informational terms; action does some of the categorization work (e.g. 'I act confident therefore I am confident') and continuously participates in the dynamic emotion categorization process over time, from which experience arises. Emotion unfolds from action and categorization but, of course, we can have diffuse affective experience without categorization (such as the experience of core affect), which suggests further that action and states of the body play a constituting role in emotional experience.

To summarise, it would be an oversimplification of the emotion categorization process to say that the body and environment 'feed' the nervous system information; categorization and action form feedback loops for a dynamic interaction with the environment. This is what makes us flexible organisms able to learn from our past. 
This also means that the categorization system works with representations but that's not to say that a person only acts through them; the dynamical system ${ }^{2}$ gives action a constitutive role in determining the emotion concept applied and how further actions may play out. This version of Barrett might not be palatable to all enactivists (especially the radical kind) but from the interpretation of Barrett's account I have taken above, it isn't wholly incompatible. This is the account of Barrett's I take forward; it may not be completely faithful to her own language but I find it sufficiently 'Barrettian' to attribute it to her.

\subsection{Merleau-Ponty's account of thought}

In order to have a more complete picture of RT, and thus a more plausible account, we must not only have an explanation of why dysphoric ruminators have the same or similar affectual experiences but also the repetition of the same or similar propositional thoughts. Merleau-Ponty's embodied theory of perception is an appropriate fit for understanding the relationship between the personal and sub-personal levels in Barrett's theory because he similarly places the body and action as constitutive aspects of meaning-making behaviour and so, given this, his thought has significant overlap with Barrett's. Importantly, Merleau-Ponty continues to be relevant in embodied cognition within current Cognitive Science (see, for example, Thompson, 2010; Gallagher \& Zahavi, 2012) and the inclusion of his theory of mind and, more narrowly, his understanding of thought and language allows us to make the necessary steps to understanding how thoughts of a particular affective tone become 'stuck'. I do not have the space here to argue why Merleau-Ponty's account specifically is correct, but, given that Barrett's account of affect relies on interoceptive signals and bodily action, an embodied account of cognition seems the most plausible candidate for drawing connections between the various levels that the phenomenon of RT takes place on.

In Phenomenology of Perception (2012), Merleau-Ponty argues that thought and language are inextricably intertwined; there is no thought that comes before language that our words simply describe, but, instead, language "accomplishes thought" (p. 182) Our inner monologue, to elaborate, is not a result of us putting thoughts or

\footnotetext{
${ }^{2}$ I see my appropriation of Barrett's framework in this paper to share significant overlap with the dynamical patterns model of emotions put forth by Colombetti in The Feeling Body (2014). For instance, both models describe emotional experiences as emergent from processes that integrate information from the body and the world over time. However, Colombetti has been critical of Barrett's model, accusing the theory of constructed emotion of "[writing] off any role of biological influences in structuring our emotional behaviour" (p.16/48, 2014). While I agree that Barrett overstates the power of our psychological apparatus to the detriment of her theory, I think it would be uncharitable to completely dismiss her theory on this basis (and, indeed, I try to pry away a more workable framework from her strong commitment to the influence of language below). While Colombetti (2009) usefully describes all the way in which language can influence our affective experiences, it is less clear how it does so, which seems key to understanding why rumination is the ways that it is. I thus find it essential to integrate into my account some of the psychological processes that Colombetti felt were too strong. However, I try to find a halfway house between the more radical enactivism of Colombetti (2014) and the occasionally cognitivist framework of Barrett by utilising Merleau-Ponty (see Sect. 2, part ii).
} 
some underlying process into words to represent our thoughts to ourselves. By way of Vygotsky, we can understand language for Merleau-Ponty as foremost an interpersonal form of expression that is internalised for the language of thought. When I point to or refer to 'the doughnut', for example, to a friend nearby who saw the whole incident with the seagull, I point to something in our shared world and guide their attention to it (see 'The Cogito', p. 387, in Phenomenology of Perception). For Merleau-Ponty, speech is just another gesture unlike any other, so speaking, and even inner speech, is a gesture on his account. I do not have room here to argue that RT is a gesture, in the same way that pointing is, but I will defend instead the weaker claim that thought is like gestures such as pointing in the way that they have worlddirected intentionality and draw attention to things.

For the individual, our thoughts are like pointing to things in the world, but the person whose attention is being drawn to the things is us. This is understood by Merleau-Ponty as a kind of bodily orientation to events in the world. He demonstrates this with the example of thinking of Pierre; when we think about a friend (in this case, Pierre) we don't think of an image or representation of the friend, we 'aim' at the friend in the world. As Merleau-Ponty puts it: "To say that I imagine Pierre is to say that I obtain a pseudo-presence of Pierre by triggering the "Pierrebehavior"' (p. 186) Following from this, by thinking repeatedly about how I suck at my job, for instance, I trigger a kind of behaviour towards my job as though I was bad at it. To relate this back to Barrett's theory, thoughts are our bodily attitude or orientation towards situations in the world in so far as our thoughts pick out things in the world to be acted upon. An attitude or orientation towards a state of affairs could be embodied in various ways; as immune responses, muscle contractions, body language etc. Barrett might argue that it is cashed out in the body in terms of core affect. The propositional thoughts we have, then, insofar as they are instantiated as embodied attitudes or 'action schemas' will be the kinds of things that get categorized by the conceptual system, in Barrett's model, and, because instances of categorization also inform the stored concepts, these propositional thoughts we say to ourselves are also going to be available later for emotional categorization (and thus have influence over different points in time). As these thoughts are categorized according to past experience, this categorization will be 'felt' or experienced by us on the personal level, which is what gives our thoughts a particular affective tone. The consequence of this is that our thoughts go on to shape how we feel and percieve things in the future, in problematic feedback loops which 'feed' into the very tools (emotion concepts) which we use to make sense of the world.

In addition to the above, Merleau-Ponty helps us answer a potential challenge for Barrett's theory from Niiya et al. (2006). Niiya, Ellsworth, and Yamaguchi found that, in a group of participants who hadn't previously come across the name for the emotion 'amae' before, these participants were still able to experience the emotion in question. This suggests that one does not need epistemic access to an emotion concept via words on the conscious level to categorize with emotion concepts on the sub-personal level and thus the two levels come apart. This is important because it would suggest that repetitive thoughts don't have a necessary connection to the sub-conscious level of emotion concepts which generate the affective experience through the processes of categorization. There's no reason to think, according to this, that our thoughts make us 
depressed or anxious. Perhaps we want to allow some fringe cases; one might entertain the thought of death or suicide, for instance, without it getting them down. However, the association between rumination and mental disorders like depression and anxiety is strong insofar as rumination is predictive of the development of these disorders (see Nolen-Hoeksema, 2000), so in the case of RT and mental disorder there does appear to be some connection, either causal or correlative, that needs to be explained.

To begin accounting for the apparent disconnect between the specific words one knows and what one experiences, I disagree with Barrett (2018) that you must have the word for that emotion in order to experience it. Given the evidence by Niiya et al. (2006), this claim is too strong and not well motivated. In addition to this, Barrett's criteria doesn't reflect our own experience; I certainly don't need to be aware or use the term 'happy' to feel happy and we sometimes have emotional experiences that appear ineffable and we can only describe figuratively (e.g. "I felt like a statue"). And we certainly do feel these emotions, even if the words or terms aren't explicit to us. However, we will have thoughts and images that may be happiness-like or statuelike. Thoughts, understood in Merleau-Ponty's terms, are embodied orientations or attitudes to the world. Because of this, I argued above, thought is bound up with and entangled with the interoceptive information Barrett sees at the core of emotional categorization. Thus, even if we lack explicit words, thoughts will be at the core of the comparing and contrasting process of emotional categorization. I think it would be sufficient then to have 'amae-like' thoughts, and therefore embody similar attitudes to 'amae' appropriate objects in the world (in this instance, affection towards loved ones that do favours for us at their own inconvenience), in order to have similar experiences, even while lacking a particular word for that experience.

What I take forward from here is an adaptation of Barrett's theory, rather than Barrett's theory proper. Her model provides us with a way to understand why ruminators entre states of dysphoria, and by coupling this with an embodied understanding of propositional thought (as in Merleau-Ponty) we take strides towards a deeper understanding of understanding the ruminative experiences of those individuals with depression and anxiety. What I have changed most significantly about Barrett's proposal is the strict requirement that one must have a word in order to experience an emotion, but this is not to say that words do not play some role in the processes of emotional experience. In Sect. 3, I will build a more complex model to capture the particularly 'sticky' qualities of rumination. So far, this model is also somewhat static; it does not show the effects of categorization over time. And thus, I will also derive from the above account a model of rumination with 'moving parts' or, to put it another way, I will describe a model that could account for change and development in one's emotion categorization to suggest how one might enter the state of being trapped in rumination, as experienced during depression and anxiety.

\section{Associated emotion concepts}

Given that events in the world and body are constantly in flux, why do people prone to RT continue to apply the same emotion concepts? It might be that the situations are judged similar enough, despite subtle variations in signals, that the particular 
emotion concepts in question continue to be relevant. Although, in some cases, people are able to reappraise their thoughts and break out of their vicious cycle, which suggests that a person need not be stuck applying the same emotion concepts - others may also appear to bear some resemblance on the situation. For instance, I might ruminate on how I'm bad at my job but losing my job might make me realise that I didn't enjoy it in the first place and now I have the opportunity to do something I am good at. Thus, what could have become a spiral of negative thoughts turns into a positive outlook on my present situation. Why can't compulsive ruminators reappraise their situations? I think we can derive an account of why this happens from my interpretation of Barrett's theory in the section previous. We can infer, I argue, that emotion concepts will become associated.

In order for repetitive thoughts to bear consistent emotional experiences or valence over time other constraints must be in place to entail the persistent negative affect experienced during RT, as similarity is not sufficient to guarantee a perpetuating cycle; similarity would not seem to satisfactorily capture the 'sticky' nature of repetitive thoughts as similar categorizations does not entail that one continues to experience negative emotions specifically. Conceivably, a 'happy' categorization might look similar to an event in the past that was previously categorized as sad (like visiting an old friend who previously had fallen on hard times but now was doing well for themselves). It could be argued that it is the very subtle differences in interoceptive and exteroceptive signals that 'tips the scales' from happy to sad, and creates the nuances between feelings of guilt, anger, shame and misery felt by people with depression, but it doesn't explain why the affective experiences of people with depression and anxiety are persistently negative in valence. Importantly, the persistent negative affectual quality to the thoughts mark the experiences as symptoms of mental disorder, alongside five other symptoms persistent over a two-week period, as part of the criteria for diagnosis of depression (see DSM-V 2013). It is the inability to reappraise a situation - to change how we feel about something - which partially characterises compulsive dysphoric rumination and given enough superficial similarity with non-negatively valenced concepts, a situation need not always be experienced consistently negatively by the perceiver. Therefore, Barrett's theory, so far, doesn't completely square with the experience of not being able to break ruminative cycles; her theory does not yet show how these sticky patterns of dysphoric rumination follow from the processes of categorizing similar experiences.

Barrett's theory better accounts for the lived experience of ruminators when we take the notion of 'similarity' of emotion concepts to its extreme. Under Barrett's theory of constructed emotion, information from the body and environment is categorized based on this information's similarity to past events; these past events are stored instances of previous acts of categorization. How we categorize information now, and how we've categorized in the past, will shape the similarity that concepts bear on each other. Emotion concepts, when used to categorize new information to guide action, will create another instance to populate the concept for comparative use at a later date. This means, the more we use the negatively valenced emotion concepts the more populated the concepts become of examples of negative emotional experiences. Theoretically, the more instances a particular emotion concept has the greater the number of combined events, inside and outside the body, that 
will bear resemblances to this concept. A further consequence of this is that emotion concepts don't just exert their influence over what we percieve and how we percieve salient things in the environment but through their associations they can skew and mould the network as a whole to form longer-lasting influences of negatively valenced categorization. This model suggests, furthermore, that the bonds between emotion concepts would be strengthened over time, i.e. the more you recall something negative the tighter the associations become, and thus avoids the implication that any and all of us fall into patterns of dysphoric rumination after one bad day.

Associated networks of emotion concepts in mental disorder need not always be negative emotions; people with Bipolar Disorder experience periods of depression and hypomania, which would suggest tight-knit networks of both negatively valenced and positively valenced emotion concepts which one switches between. Perhaps a non-clinical case of positively valenced networks would be in those people we know to be unwaveringly positive given difficult circumstances. Why these spirals are specifically and reliably negative in valence for people with depression and anxiety is because, I hypothesise, the people with those mental disorders probably had some reoccurring negative experiences which the emotion concept processes have enabled to snowball. Part of the reason that rumination becomes sticky could be that ruminators are unfortunately and unwittingly well practised; the habit has been formed from past instances of ruminative behaviour that have shaped and strengthened the associations between emotions.

Rumination gains a foothold in our emotion categorization system due its grouping of things based on similarity, following Barrett. Categorization allows for significant overlap in so far as similarity between things of any kind-in our case, interoceptive and exteroceptive information - can be broadly construed. This is where the processes of emotional categorization go awry; when we start to classify events in negative concepts, these concepts become proliferated with instances and start bearing resemblances to many more things which become categorized negatively, adding yet more instances. This is the vicious cycle in mood disorders that Bower (1981) and Teasdale (1983) describe-simply put, RT is a form of emotional domino effect. In so far as negatively valenced concepts bear resemblance to each other, these concepts would foreseeably become more tightly grouped and 'associated' ${ }^{3}$ due to their shared content. It is in this way that emotion concepts 'constrain' each other through forming tight-knit associations based on resemblance. This would explain why feelings of guilt, shame, anger, and melancholy commonly come together, especially for dysphoric individuals, and why ruminative thoughts may vary (from "I suck at my job" to "Nobody loves me") whilst still perpetuation similar negative experiences. A negatively skewed emotion concept network might also explain how sufferers of depression and anxiety might relapse or find it difficult to recover; one bad thought could lead to another and another through tapping into strongly associated emotions.

\footnotetext{
${ }^{3}$ This account of associated emotion concepts was heavily influenced by Bower's (1981) model of mood-congruent memory. Although evidence for in favour of this model is sparse (see Macleod \& Mathews, 2004), and it seems to have fallen out of favour, I think it says many of the same points I have tried to make in this section.
} 


\section{Hypo/hypercognition: why we still can't reappraise}

RT, I have argued so far, becomes increasingly compulsive and habitual as our emotion concept network gets skewed towards negative emotions. However, I argue that the nature of this skewed network is not one where emotion concepts 'drop out' or get forgotten if they aren't constantly used in the categorization process. Instead, what we lose when emotions lose association or similarity to other concepts is the ability to make meaning from environmental and bodily information. Ruminators may only see the world in terms of their repetitive negative thoughts but they can recognise that someone else is happy or that something might normally have made them happy (but they can't, in this case, experience the emotion). I claim that dysphoric ruminators move from an emotional experience of 'knowing-how' (i.e. being able to apply a concepts) to an experience of emotional 'knowing-that' (i.e. knowing that one could feel differently, or that other's feel differently, but one simply can't feel differently). I use my interpretation of Barrett to elaborate on Wu and Dunning's $(2018,2019)$ description of hypocognition. In hypocognitive states, sufferers of compulsive and negative RT don't just fall into bad patterns but are somewhat barred from changing them; my account thus far shows not only how ruminators become hypocognitive of other emotional states but also how they get stuck cycling through the same ones. Thus, I explain why some sufferers might find it impossible to help themselves out of ruminative cycles, even if they are actively trying to. Through the theory of hypocognition and hypercognition we can understand that emotion concepts aren't simply forgotten but unable to be meaningfully used, and, further to this, overcoming ruminative behaviour isn't as simple as reappraising. Looking at the same situation through a different emotional lens could prove almost impossible. I suggest that this is how we ought to look at acute cases of RT, like those in depression and anxiety.

To be hypocognitive means you lack a certain concept or schematic for a concept, which includes the necessary knowledge to represent, organize, and make meaning from things or events in the world (Wu \& Dunning, 2018). Wu and Dunning $(2018,2019,2020)$ follow the similar school of thought as Barrett (above) that concepts are needed to make sense of the world but, they add, lacking certain concepts or the overuse of some concepts (termed 'hypercognition') shapes our cognitive experiences (through what we can remember, identify and recognise: Wu \& Dunning, 2019). For example, in an experiment comparing the ability of North-American participants to remember familiar versus unfamiliar fruit, Wu and Dunning (2019) found that participants showed a bias towards not recognising culturally unfamiliar fruit rather than familiar fruit. ${ }^{4}$ Ruminators would become hypocognitive of some emotion concepts (like happiness) through

\footnotetext{
${ }^{4}$ It is important to note here, to avoid confusion with the word 'concept', that Wu and Dunning use it in the traditional sense of an abstract idea (something we might typically name, like 'apple' or 'strawberry') opposed to Barrett's informational kind of concept as stored 'multimodal summaries'. However, I have reason to think that these two senses of concept are not unrelated, but more on that above.
} 
repeated application of the same emotion concepts (in the process of hypercognition), which is facilitated by the associations made in the network of emotions. Often unaware of what concepts we are missing, we often assume we experience the world in totality (an experience called the Totality Illusion: Wu \& Dunning, 2018). This would explain why some ruminators report greater insight or understanding of their problems when, relative to other problem-solving strategies, it actually doesn't help that much (Kingston et al., 2014). Experiences of insight or understanding may be due to the fact that people who are dysphoric may think they have grasped the whole picture, when in actual fact they are hypocognitive of important or alternative concepts relating to their problem.

However, in the case of RT, emotion concepts aren't totally missing; we may still be aware, although depressed and anxious, that others around us are happy or content. What we become hypocognitive of during RT, then, is not the concept itself-it doesn't drop out of existence-but the action-schema of the concept to make meaning from the world. Indeed, this is what I argue is going on even in Wu and Dunning's fruit case study; emotion concepts as well as concepts for 'things' we identify in the world (like types of fruit) include plans for appropriate actions. As I argued in Sect. 2, the kinds of thoughts we have on the conscious level are bound to the emotional categorization processes happening beneath our conscious awarenessthought being cashed out as embodied orientation or a kind of 'action readiness', along the lines of Merleau-Ponty (2012). The fruit concepts Wu and Dunning discuss will also be enmeshed within this emotion categorization process as, to have an idea of them, to recognise them or even just to imagine them, under Merleau-Ponty, is to have an embodied orientation towards them. This preparedness for action, will carry with it its own interoceptive signals which, as I've discussed, is what gets categorised using our emotion concepts. In relation to hypocognition, what we lose is the ability to meaningfully act on or orientate ourselves towards particular features of the world, encapsulated in linguistic thought. Someone who is hypocognitive of a 'durian', for instance, will not have access to the same embodied meaning-making actions of those who are familiar with the fruit. They would lack, below the personal level, the kinds of stored information about interoceptive patterns and appropriate actions that make up Barrett's kinds of concepts. It is not as simple as missing the word 'durian'; a person lacking conscious epistemic access to the name of the fruit is lacking access to embodied, sub-personal knowledge in the fruit instantiated in the multimodal summaries Barrett argues we use to categorise things. This would mean that someone would not only fail to recognise the fruit but also struggle to appropriately interact with it.

Knowing what a durian is, is to have a kind of 'durian-attitude' which are stored behaviours and ways of interacting with this particular fruit. Emotion concepts, for Barrett, are also kinds of stored plans for action; they guide us in appropriate ways of acting. In this way, an emotion concept like 'happiness' or 'fear' is going to be a concept much like 'durian' because they guide particular actions in the world and to have the 'concept' (used both in the sense of Wu and Dunning, and Barrett) is to have a schema or plan for one's body to interact with whatever is the object of the concept. Words don't seem to be necessary to have the experience of an emotion (see discussion on Niiya et al., 2006, in Sect. 2) so long as there is some kind of 
embodied, actionable schema from which the comparisons are made in the categorization process. To be hypocognitive, I conclude, is to lack or have limited access to an embodied, actionable schema. What this means for the ruminator is that they don't lack the terms or understanding for more positive emotions, instead, they unable to enact positive emotions. ${ }^{5}$ This is what makes the difference, I suggest, between someone of a mere pessimistic disposition and someone with a pathological tendency to ruminate; it is not simply the case that people with severe depression and anxiety rely on emotion concepts like sadness and fear to make sense of their world, they are incapable of using other embodied schemas to do so (because of the tight-knit associations in the networks of these emotion concepts and action schemas).

My account thus far also suggests that being hypocognitive is likely to be a matter of degree in so far as resemblance between concepts (and thus how closely they are associated) comes in degrees. People in a hypocognitive state will be those whose emotion concept network has become so tightly bound that some concepts are not able to be used to make meaning from new information; we go from a kind of embodied knowing-how (e.g., "this is a happy event for me and I feel happy") to an embodied knowing-that (e.g., "that might be a happy event for someone but it's not happy for me and I don't feel happy") for the emotion concepts. However, being hypocognitive would be a dynamic state; through associations our network of emotion concepts can become skewed in many different directions and in different strengths. Many people don't start of as ruminators, and not everyone is destined to ruminate forever, and so by understanding hypocognition as a sliding scale we can hypothesise that someone becomes stuck in a ruminative cycle gradually.

In addition to the above, because emotion concepts are actionable and shape our perception of the environment, ${ }^{6} \mathrm{RT}$ will preclude us from changing the situation we are in and thus breaking out of our particular cycle of thought. Because the use of particular groupings of concepts can become 'sticky' through particularly strong associations, shaped by the past, looking towards the future is also going to involve become hypocognitive of alternative outcomes. This explains why people with depression are generally pessimistic about the future and people with anxiety are fearful of it. I suggest that given the models I have discussed, people with severe depression and anxiety find it difficult or, in some cases, cannot think otherwise. And because concepts guide actions, people who ruminate are likely to be drawn towards or act such that negative cognitions are confirmed. Meaning, feeling anxious about some unknown situation, and applying concepts of fear, may guide avoidance behaviour which feeds into the fear of the unknown situation and thus precludes the possibility of confronting the fear and reappraising. That is not to say we should throw people with anxiety into situations that they are afraid of to prove it

\footnotetext{
5 This might also explain experiences of lack of agency in mood disorders like depression (see Slaby et al., 2013).

${ }^{6}$ RT may also importantly change what we see as salient or affordable in the environment itself (see De Haan et al., 2013), which means what actions appear possible or impossible for us could be shaped over extended periods of time due to recurrent affective experiences.
} 
isn't as bad as it seems, but the example demonstrates how dysphoria can exacerbate a kind of emotional confirmation bias.

To summarise, when groups of emotion concepts become strongly associated, it is not simply the case that we use the same emotion concepts to categorize new information over and over again. The other side of this coin is hypocognition; during extreme periods of dysphoric rumination, individuals aren't just skewed towards seeing the world through a negative lens but, in addition to this, they are also barred from making meaning from the same information using concepts outside this hypercognised group. Through understanding our conceptual apparatus as one grounded in bodily action we can understand how a person, once they've developed a bad cognitive habit, can be stuck in a pattern and can struggle to find a way out. By adapting Barrett we can say how this habit develops and shapes our conceptual system over time, and alongside Wu and Dunning's understanding of hypocognitive states we can understand why this habit sticks around.

\section{Conclusion}

Any position that holds that our thoughts are contained within our skulls and are harmless should be thrown out. What my examination of RT has shown is that thoughts can become recalcitrant, shape perception and guide action-and not always for the better. Moreover, when our thoughts become repetitive to the point where we feel like we are stuck on repeat, our recurrent thoughts can result in longterm suffering.

RT preys on the kinds of mechanisms of emotion and cognition that we all have so anyone can be prone to depressive or anxious rumination, although some people slip into those unhealthy habits more than others. Further to this, my application of models of emotion concepts to the problem of RT has important suggestions for therapy. Given that some emotion concepts can be bound up with explicit cognitions, my analysis suggests particularly that therapies such as CBT that deal with the pathological patterns of thinking will be helpful in treating rumination. Moreover, my analysis supports the principles that CBT are built upon, i.e. that certain patterns of behaviour are learnt and we can be made aware of them and even change them. However, the argument I have laid out would also support the availability of a plethora of different treatment methods, given that the conceptual system that enables ruminative thought is implemented on multiple levels (from the physiological, environmental, and first-person, psychological levels). In so far as intervention at any of these levels results in a change in the way someone emotionally categorises a situation, multiple forms of therapies that target these various levels suggest themselves (such as medication, CBT, arts based therapies, network therapy etc.) Barrett's model makes one's conceptual network extremely individual, in so far as it is moulded by our personal history and our current circumstances, which suggests that any form of therapy will be highly individualistic too. My argument suggests, therefore, there is no 'one-size-fits-all' treatment for severe dysphoric rumination and the 
sensitive interplay of one's environment, bodily needs, psychological concepts, and the content negative thoughts needs to be considered in each case.

My analysis would explain the conclusion of Lyubomirsky and Nolen-Hoeksema, that dysphoric rumination is not an effective problem-solving strategy. This is because RT excludes the kinds of concepts necessary for adopting different perspectives on a problem and thus prevents us from taking action that might alleviate the recurrent negative affect. Moreover, while Watkins and Baracaia (2001) provide us with reasons one might have for deciding to ruminate, my analysis goes one step further to explain why it become compulsive even if one had beliefs that it doesn't help. Therefore, this model has a potentially large explanatory power, with the potential to explain not only how RT develops from moderate to severe cases but also associated phenomena that come along with RT (e.g. its compulsiveness, its continued perpetual use, its use in the first place as an emotion regulation strategy).

A great deal more needs to be said about how emotion concepts are developed in the first place and how similarity is judged between them (for Barrett, that answer lies in that emotion concepts encode certain information about predictive successsee Barrett, 2017-on which similarity can be judged). Having said this, I have laid out a new framework for discussing the behaviour of repetitive thought in terms of emotion concepts, which provides a potential target for investigation moving forward, for therapy, and for discussing the nature of affective disorders and their symptoms. I have also expanded Barrett's original framework for emotional experience to explain how we can get stuck with similar emotional experiences (through associated emotion concepts and excluded emotion concepts) typically experienced by people who ruminate dysphorically.

Acknowledgements I would like to thank the contributions of my supervisors Dave Ward, Alistair Isaac, and Tillmann Vierkant for their helpful feedback at various stages of this paper. I would also like to give my thanks to the Active Mind Lab, a community of friendly philosophers of mind, who have been influential on all my research. Particular thanks go to Adriana Alcaraz-Sánchez for her constructive feedback. Lastly, my thanks also go to the two anonymous reviewers, whose fair and discerning criticism has made this paper much stronger.

Funding Research supported by the Scottish Graduate School for Arts and Humanities.

Availability of data and material N/A.

\section{Declarations}

Conflicts of interest The author has no conflicts of interest to declare that are relevant to the content of this article.

Code availability N/A.

Open Access This article is licensed under a Creative Commons Attribution 4.0 International License, which permits use, sharing, adaptation, distribution and reproduction in any medium or format, as long as you give appropriate credit to the original author(s) and the source, provide a link to the Creative Commons licence, and indicate if changes were made. The images or other third party material in this article are included in the article's Creative Commons licence, unless indicated otherwise in a credit line to the material. If material is not included in the article's Creative Commons licence and your intended use is not permitted by statutory regulation or exceeds the permitted use, you will need to obtain permission 
directly from the copyright holder. To view a copy of this licence, visit http://creativecommons.org/licen ses/by/4.0/.

\section{References}

Aldao, A., \& Nolen-Hoeksema, S. (2012). When are adaptive strategies most predictive of psychopathology? Journal of Abnormal Psychology, 121(1), 276.

Antrobus, M., \& Bortolotti, L. (2016). Depressive delusions. Filosofia Unisinos, 17(2), 192-201.

Barrett, L. F. (2006). Solving the emotion paradox: Categorization and the experience of emotion. Personality and Social Psychology Review, 10(1), 20-46.

Barrett, L. F. (2011). Constructing emotion. Psychological Topics., 20(3), 359-380.

Barrett, L. F. (2014). The conceptual act theory: A précis. Emotion Review, 6(4), 292-297.

Barrett, L. F. (2017). The theory of constructed emotion: An active inference account of interoception and categorization. Social Cognitive and Affective Neuroscience, 12(1), 1-23.

Barrett, L. F. (2018). How emotions are made: The secret life of the brain. Pan Macmillan.

Barrett, L. F., Quigley, K. S., \& Hamilton, P. (2016). An active inference theory of allostasis and interoception in depression. Philosophical Transactions of the Royal Society b: Biological Sciences, 371(1708), 20160011.

Barrett, L. F., Wilson-Mendenhall, C. D., \& Barsalou, L. W. (2014). A psychological construction account of emotion regulation and dysregulation: The role of situated conceptualizations. In J. J. Gross (Ed.), Handbook of emotion regulation (pp. 447-465). Guilford Press.

Boncompagni, A. (2013). Enactivism and the 'Explanatory Trap'. A Wittgensteinian Perspective. Methode - Analytic Perspectives, 2, 27-49.

Bower, G. H. (1981). Mood and memory. American Psychologist, 36(2), 129.

Colombetti, G. (2009). What language does to feelings. Journal of Consciousness Studies, 16, 4-26.

Colombetti, G. (2013). Psychopathology and the enactive mind”. In K. W. M. Fulford, M. Davies, R. G. T. Gipps, G. Graham, J. Z. Sadler, G. Stanghellini, \& T. Thornton (Eds.), The oxford handbook of philosophy and psychiatry (pp. 1083-1102). Oxford University Press.

Colombetti, G. (2014). The feeling body: Affective science meets the enactive mind. The MIT Press.

De Haan, S., Rietveld, E., Stokhof, M., \& Denys, D. (2013). The phenomenology of deep brain stimulation-induced changes in OCD: An enactive affordance-based model. Frontiers in Human Neuroscience, $7,653$.

Di Paolo, E. A. (2005). Autopoiesis, adaptivity, teleology, agency. Phenomenology and the Cognitive Sciences, 4(4), 429-452.

DiPaolo, E. A., \& Thompson, E. (2014). The enactive approach. In L. Shapiro (Ed.), The Routledge handbook of embodied cognition (pp. 68-78). Routledge.

Fuchs, T. (2013). "The phenomenology of affectivity." In The Oxford handbook of philosophy and psychiatry, eds. K.W.M. Fulford, Martin Davies, Richard G.T. Gipps, George Graham, John Z. Sadler, Giovanni Stanghellini, and Tim Thornton, Oxford: Oxford University Press, pp.612-631

Gallagher, S., \& Zahavi, D. (2012). The Phenomenological Mind. Taylor and Francis Group.

Jelscha, S. (2018). Disordered existentiality: Mental illness and Heidegger's philosophy of Dasein. Phenomenology and the Cognitive Sciences, 17(3), 485-502.

Kingston, R. E. F., Watkins, E. R., \& Nolen-Hoeksema, S. (2014). Investigating functional properties of depressive rumination: Insight and avoidance. Journal of Experimental Psychopathology, 5(3), 244-258.

Kurth, C. (2018). The anxious mind: An investigation into the varieties and virtues of anxiety. MIT Press

Lyubomirsky, S., \& Nolen-Hoeksema, S. (1995). Effects of self-focused rumination on negative thinking and interpersonal problem solving. Journal of Personality and Social Psychology, 69(1), 176.

Macleod, C., and Mathews, A. (2004). "Selective Memory Effects in Anxiety Disorders: An Overview of Research Findings and their Implications." In Memory and Emotion, by Daniel Reisberg and Paula Hertel, eds., New York: Oxford University Press, 2004. Oxford Scholarship Online, 2012. doi: https://doi.org/10.1093/acprof:oso/9780195158564.003.0005.

Maiese, M. (2020). An enactivist approach to treating depression: Cultivating online intelligence through dance and music. Phenomenology and the Cognitive Sciences, 19, 523-547. 
McLaughlin, K. A., \& Nolen-Hoeksema, S. (2011). Rumination as a transdiagnostic factor in depression and anxiety. Behaviour Research and Therapy, 49(3), 186-193.

Merleau-Ponty, M. (2012). Phenomenology of Perception, Taylor and Francis Group, 2012. (Online), ProQuest Ebook Central, Available: https://ebookcentral.proquest.com/lib/ed/detail.action?docID= 1433878. [Accessed: 29/12/20]

Michaelian, K. and Sant'Anna, A. (2019). "Memory without content? Radical enactivism and (post) causal theories of memory." Synthese, pp.1-29.

Niiya, Y., Ellsworth, P. C., \& Yamaguchi, S. (2006). Amae in Japan and the United States: An exploration of a" culturally unique" emotion. Emotion, 6(2), 279.

Nolen-Hoeksema, S. (1991). Responses to depression and their effects on the duration of depressive episodes. Journal of Abnormal Psychology, 100(4), 569.

Nolen-Hoeksema, S. (2000). The role of rumination in depressive disorders and mixed anxiety/depressive symptoms. Journal of Abnormal Psychology, 109(3), 504.

Ratcliffe, M. (2018). The interpersonal structure of depression. Psychoanalytic Psychotherapy, 32(2), $122-139$.

Russell, J. A. (2003). Core affect and the psychological construction of emotion. Psychological Review, 110(1), 145.

Slaby, J., Paskaleva, A., \& Stephan, A. (2013). Enactive emotion and impaired agency in depression. Journal of Consciousness Studies, 20(7-8), 33-55.

Teasdale, J. D. (1983). Negative thinking in depression: Cause, effect, or reciprocal relationship? Advances in Behaviour Research and Therapy, 5(1), 3-25.

Teasdale, J. D. (1988). Cognitive vulnerability to persistent depression. Cognition and Emotion, 2(3), $247-274$.

Thompson, E. (2010). Mind in life. Harvard University Press.

Vazard, J. (2019). (Un) reasonable doubt as affective experience: obsessive-compulsive disorder, epistemic anxiety and the feeling of uncertainty. Synthese, 198, 1-18.

Ward, D., Silverman, D., \& Villalobos, M. (2017). Introduction: The varieties of enactivism. Topoi, 36, 365-375.

Watkins, E. (2008). Constructive and unconstructive repetitive thought. Psychological Bulletin, 134(2), 163.

Watkins, E., \& Baracaia, S. (2001). Why do people ruminate in dysphoric moods? Personality and Individual Differences, 30(5), 723-734.

Wu, K., \& Dunning, D. (2018). Hypocognition: Making sense of the landscape beyond one's conceptual reach. Review of General Psychology, 22(1), 25-35.

Wu, K. \& Dunning D. (2019). Hypocognitive mind: How lack of conceptual knowledge confines what people see and remember. https://doi.org/10.31234/osf.io/29ryz

Wu, K. \& Dunning D. (2020) Hypocognition and the invisibility of social privilege. https://doi.org/10. 31234/osf.io/5ge79

Publisher's Note Springer Nature remains neutral with regard to jurisdictional claims in published maps and institutional affiliations. 